ISSN 0258-7122

Bangladesh J. Agril. Res. 33(3) : 493-502, September 2008

\title{
ENDOGENOUS HORMONAL CONTENT DURING GRAIN DEVELOPMENT IN HEXAPLOID AND TETRAPLOID WHEAT
}

\author{
SRIDHAR GUTAM ${ }^{1}$, VIRENDRA NATH ${ }^{2}$ AND G.C. SRIVASTAVA ${ }^{3}$
}

\begin{abstract}
A pot experiment was conducted in the rabi (post rainy) seasons of 2001 and 2002 to study the genotypic differences in grain growth rate and endogenous hormonal content in the developing grains of hexaploid and tetraploid wheat. The endogenous hormonal contents of grains in both the ploidy levels had changed in sequence. At 5 days after anthesis (DAA), gibberellic acid $\left(\mathrm{GA}_{3}\right)$; at 15 DAA (rapid growth phase), indole-acetic acid (IAA); at 25 DAA (dough stage), abscisic acid (ABA) were maximum. At 35 DAA, all the endogenous hormonal level decreased and among the hormones, ABA was highest followed by IAA and $\mathrm{GA}_{3}$. Hexaploids recorded higher concentrations of endogenous hormones (13.38\% IAA, $17.89 \% \mathrm{GA}_{3}$, and $14.7 \% \mathrm{ABA}$ ) on fresh weight basis and resulted in higher seed weight ( $56.99 \mathrm{mg} /$ grain) and grain growth rate (0.009 $\mathrm{g} / \mathrm{g} /$ day) compared to tetraploids ( $49.08 \mathrm{mg} / \mathrm{grain} ; 0.008 \mathrm{~g} / \mathrm{g} / \mathrm{day}$ ) on dry weight basis by better mobilization of photosynthates during grain filling.
\end{abstract}

Key Words: Grain growth rate, hormones, indole-acetic acid, gibberellic acid, abscisic acid.

\section{Introduction}

The development of new plant architecture with semi-dwarf types replacing the traditional tall types resulted in increasing wheat yields from $1000 \mathrm{~kg} / \mathrm{ha}$ in early 1960 's to nearly $2900 \mathrm{~kg} / \mathrm{ha}$ in late 1990's was a remarkable achievement, due to which, India witnessed green revolution. Still, to keep pace with the burgeoning population, it is expected that India would need more than 100 million tons of wheat (2006-07 production) and with the productivity more than that of the present level (4000 kg/ha). Efforts are being made in this direction and the Indian Agricultural Research Institute (IARI), New Delhi has initiated strategic research to develop new plant types a way back in 1994-95. The process of creating a new variety takes several years. Nevertheless, the new plant types (hexaploids) developed at IARI in 2000 has large panicles, higher number of grains per spike, 1000-grain weight, biomass and increased sink size. Efficient assimilate partitioning has generally being considered as a factor in the regulation of plant productivity, but the basis of its control has not been fully exploited. The genotypic variation in grain weight of wheat results from the interaction between

\footnotetext{
${ }^{1-3}$ Division of Plant Physiology, Indian Agricultural Research Institute, New Delhi 110012, India.
} 
potential storage capacity or volume and realization of this potential. The variation in grain filling is also the result of interaction between the availability of assimilates to the grain, metabolism of intermediates and synthesizing complex (Jenner and Rathjen, 1978).

The question, thus, arises is what is the basis for differences in translocation behaviour between cultivars (Bhardwaj and Verma 1985). There are reports that auxins, gibberellins, abscisic acid are involved in the regulation of grain development (Hansen and Grossmann, 2000). Suggestions have been made that plant hormones exert regulatory effects on the direction and rate of translocation of assimilates (Wardlaw and Moncur, 1976). In a study (Sivakumar et al., 2001) of shriveling problem (poorly filled grains) in triticale, Benzyl adenine (BA) treatment increased grain dry matter accumulation, which in turn resulted in better filling of grains and increased grain weight. Thus, it appears that variation in grain weight between wheat and triticale might be due to different availabilities of growth promoting hormones, such as cytokinins (CKs) and assimilates. However, little is known about the grain filling rate, which is a key factor in increasing the yield potential of new plant types developed at IARI, and whether and how plant hormones are involved in the process. Keeping this in view, the present work regarding grain filling rate among hexaploid and tetraploid wheat genotypes, grain development, and endogenous levels of indoleacetic acid (IAA), gibberellic. acid ( $\left.\mathrm{GA}_{3}\right)$ and abscisic acid (ABA) during post anthesis was initiated.

\section{Materials and Method}

Plant materials: Experiments were carried out during Rabi seasons of 2001-02 and 2002-03 in the Division of Plant Physiology, Indian Agricultural Research Institute, New Delhi. A set of three hexaploids (DL-1266-1, DL-1266-2, and PBW-343) and another set of three tetraploids (HD-530, HI-8498, and PDW233) were grown in cement pots of dimensions $30 \times 30 \times 50 \mathrm{~cm}^{3}$. Each pot was filled with sandy loam soil mixed with sufficient quantity of FYM and the recommended doses of $\mathrm{N}, \mathrm{P} \& \mathrm{~K}$ were applied to the soil before filling up the pots. Split doses of nitrogen was also applied at mid-tillering and at panicle initiation stages. Sufficient seeds were sown in each pot and later the plants were thinned to nine plants per pot and adequately watered daily to maintain the soil close to the field capacity throughout the crop growth period.

Sampling procedure: The heading and flowering dates of individual panicles were labeled and recorded. Ten to twelve labeled panicles were sampled at 5, 15, 25 and 35, days after anthesis (DAA) in each variety. The spikelets were divided 
into two parts: one was frozen in liquid nitrogen for hormonal assay and the other one dried in oven at $80^{\circ} \mathrm{C}$ till a constant weight was achieved. Then, dehulled and weighed for determing the grain growth rate.

Grain growth rate (GGR): Grain growth rate of ear was recorded at an interval of 10 days from 5-35 DAA and at maturity according to Zhu et al. (1988).

Grain growth rate $=\frac{\log _{e} w_{2}-\log _{e} w_{1}}{t_{1}-t_{1}} \mathrm{~g} / \mathrm{g} /$ day

Where, $w_{1}$ and $w_{2}$ are dry weights of grains at time $t_{1}$ and $t_{2}$, respectively.

Hormone extraction procedure: The method for the extraction and purification of endogenous plant hormones IAA, $\mathrm{GA}_{3}$, and ABA were modified from those described by Sundberg (1990), Kojima (1995), and Yang et al. (2000). Samples corresponding to $4 \mathrm{~g}$ dehulled and frozen grains were homogenized in a morter and pestle (on ice) with $80 \%(\mathrm{v} / \mathrm{v})$ methanol supplemented with $10 \mathrm{mg} / \mathrm{l}$ butylated hydroxytoluene (BHT) as an antioxidant. The homogenate was filtered and the solid residue was further extracted twice with the same solvent. The methanolic extracts were kept for continuous stirring at $4^{\circ} \mathrm{C}$ in the dark for about 4 hours and centrifuged at 10,000 rpm for 10 minutes at the same temperature. The supernatant was combined and concentrated to a water residue in vacuum at $40^{\circ} \mathrm{C}$ by rotatory evaporation. The volume was adjusted to $10 \mathrm{ml}$ with $0.05 \mathrm{M}$ Na-phosphate buffer, $\mathrm{pH} 7.5$, and neutral compounds were removed by partitioning with $2 \times 5 \mathrm{ml}$ fresh diethyl ether in a $20 \mathrm{ml}$ glass vial. The ether was layered to the aqueous phase and the two-phase system was gently stirred for 3 minutes on a multi-point magnetic stirrer. After discarding the ether phase, the aqueous phase was adjusted to $\mathrm{pH}$ 2.7 with $1 \mathrm{M} \mathrm{HC1}$ and partitioned as described above with $3 \times 5 \mathrm{ml}$ fresh diethyl ether. Saving the aqueous phase for further purification of gibberellins, the combined ether phases were reduced to dryness (anhydrous $\mathrm{Na}_{2} \mathrm{SO}_{4}$ was added to remove water from the ether phase) and used for the estimation of IAA and ABA.

The aqueous phase after partitioning against diethyl ether was partitioned two times against $10 \mathrm{ml}$ of ethyl acetate and the aqueous phase was discarded. The ethyl acetate layer was partitioned two times against $10 \mathrm{ml}$ of $0.2 \mathrm{M}$ $\mathrm{K}_{2} \mathrm{HPO}_{4}$ and the organic layer was discarded. The aqueous phase was adjusted to $\mathrm{pH} 2.5$ with $\mathrm{H}_{3} \mathrm{PO}_{4}$. The acidified phase was partitioned two times against 10 $\mathrm{ml}$ of ethyl acetate. The ethyl acetate layer was dried over anhydrous $\mathrm{Na}_{2} \mathrm{SO}_{4}$ overnight and used for the estimation of $\mathrm{GA}_{3}$. 
Hormone analysis: The dried extracted samples were reconstituted in $5 \mathrm{ml}$ HPLC grade methanol and were analyzed by high performance liquid chromatograph (HPLC) of the make Thermo Separation Product model Spectra System P2000, equipped with a variable wavelength UV-150, UV-VIS detector and a Rheodyne injector (20 $\mu \mathrm{l}$ loop), and connected to Datajet reporting integrator. The chromatographic conditions were, Li-Chrosorb RP $18(7 \mu \mathrm{m})$ packed in a stainless steel column $(250 \mathrm{~mm} \times 4.6 \mathrm{~mm}$ i.d.) as stationary phase, methanol: water $(60: 40 \mathrm{v} / \mathrm{v})$ as mobile phase. The flow rate was kept at 0.7 $\mathrm{mI} / \mathrm{min}$ and the detection was done at $265 \mathrm{~nm}$ (sensitivity: 0.08 a.u.f.s). The retention time of the peaks in authentic hormones and in the samples obtained by the chromatograph was compared and the peak area was measured with single channel computing integrator and was used to quantify the amount of hormone present in the sample.

Statistical analysis: The experimental data was subjected to statistical analysis following completely randomized block design as described by Panse and Sukhatme (1967). Duncan's Multiple Range Test (DMRT) was carried out by using the software MSTAT-C (Ver. 2.10) developed by Michigan State University, USA to know the significant difference among genotypes.

\section{Results and Discussion}

Seed weight (mg/grain): The significant differences in seed weight between all the genotypes at all the stages were observed (Table 1). It was also observed that the seed weight increased continuously from 5 DAA until harvest in all the genotypes, irrespective of its ploidy level. Hexaploids had significantly higher seed weight than tetraploids at all the stages. However, only two hexaploid genotypes, DL-1266-1 and DL-1266-2 recorded significantly higher seed weight, while all other genotypes did not differ significantly with each other. At 15 DAA also, the genotypes DL-1266-l and DL-1266-2 had significantly higher seed weight than other genotypes except HI-8498. Here at this stage and the lowest seed weight (11.83 mg) was recorded in HD-4530 of tetraploids. At 25 DAA and other later stages, the genotypes DL-1266-1 and DL-1266-2 among hexaploids had significantly higher seed weight compared to all other genotypes though they were at par with each other. At harvest, DL-1266-1 and DL-1266-2 of hexaploids recorded significantly higher seed weight of $60.15 \mathrm{mg}$ and $61.25 \mathrm{mg}$, respectively, over all other genotypes, while all other genotypes were at much lower weights and showed no significant differences with each other. It indicates that the newly developed hexaploid lines had higher yielding capacities than the existing hexaploids and tetraploids. Capacity of the grain to accumulate 
Table 1. Genotypic differences in seed weight (mg/grain dry wt) and grain growth rate (gig/day dry wt) among hexaploid and tertaploid wheat.

\begin{tabular}{|c|c|c|c|c|c|c|c|c|c|}
\hline \multirow{3}{*}{ Genotypes } & \multicolumn{9}{|c|}{ Days after anthesis } \\
\hline & 5 & $5-15$ & 15 & $15-25$ & 25 & $25-35$ & 35 & 35-Harvest & Harvest \\
\hline & Seed wt & $\begin{array}{c}\text { Grain } \\
\text { growth rate }\end{array}$ & Seed wt & $\begin{array}{c}\text { Grain } \\
\text { growth rate }\end{array}$ & Seed wt & $\begin{array}{c}\text { Grain } \\
\text { growth rate }\end{array}$ & Seed wt & $\begin{array}{c}\text { Grain } \\
\text { growth rate }\end{array}$ & Seed wt \\
\hline DL-1266-1 & $6.27^{\mathrm{a}^{*}}$ & $0.091^{\mathrm{a}}$ & $15.56^{\mathrm{a}}$ & $0.088^{\mathrm{a}}$ & $37.57^{\mathrm{a}}$ & $0.041 \mathrm{a}$ & $54.89^{\mathrm{a}}$ & $0.009^{\mathrm{a}}$ & $60.15^{\mathrm{a}}$ \\
\hline DL-1266-2 & $6.43^{\mathrm{a}}$ & $0.093^{\mathrm{a}}$ & $16.35^{\mathrm{a}}$ & $0.086^{\mathrm{a}}$ & $38.47^{\mathrm{a}}$ & $0.037^{\mathrm{abc}}$ & $56.12^{\mathrm{a}}$ & $0.009^{\mathrm{a}}$ & $61.25^{\mathrm{a}}$ \\
\hline PBW-343 & $5.24^{\mathrm{b}}$ & $0.092^{\mathrm{a}}$ & $13.15^{\mathrm{bc}}$ & $0.084^{\mathrm{ab}}$ & $30.56^{\mathrm{b}}$ & $0.039^{\mathrm{ab}}$ & $45.27^{\mathrm{b}}$ & $0.009^{\mathrm{a}}$ & $49.58^{\mathrm{b}}$ \\
\hline Sub mean & 5.98 & $0.092^{\mathrm{a}}$ & 15.02 & 0.086 & 35.53 & 0.039 & 52.09 & 0.009 & 56.99 \\
\hline \multicolumn{10}{|l|}{ Tetraploids } \\
\hline DW-233 & $517^{\mathrm{b}}$ & $0.086^{\mathrm{ab}}$ & $12.26^{\mathrm{bc}}$ & $0.085^{\mathrm{a}}$ & $28.69^{\mathrm{b}}$ & $0.034^{\mathrm{bc}}$ & $40.35^{\mathrm{b}}$ & 0.008 & $43.69^{b}$ \\
\hline D-4530 & $5.12^{\mathrm{b}}$ & $0.079^{\mathrm{b}}$ & $11.83^{\mathrm{C}}$ & $0.079^{\mathrm{bc}}$ & $26.14^{\mathrm{b}}$ & $0.033^{c}$ & $36.45^{\mathrm{b}}$ & $0.009^{\mathrm{a}}$ & $39.54^{\mathrm{b}}$ \\
\hline HI-8498 & $527^{\mathrm{b}}$ & $0.077^{\mathrm{b}}$ & $14.29^{\mathrm{ab}}$ & $0.077^{\mathrm{C}}$ & $26.57^{\mathrm{b}}$ & $0.033^{\mathrm{C}}$ & $37.12^{\mathrm{b}}$ & $0.008^{\mathrm{a}}$ & $40.26^{\mathrm{b}}$ \\
\hline Sub mean & 5.19 & 0.081 & 12.80 & 0.080 & 27.13 & 0.033 & 37.97 & $0.008^{\mathrm{a}}$ & 41.16 \\
\hline Total mean & 5.58 & 0.086 & 13.91 & 0.083 & 31.33 & 0.036 & 45.03 & 0.009 & 49.08 \\
\hline
\end{tabular}

* Duncan's Multiple Range Test. In a column, means followed by a common letter are not significantly different at 5\% level. 
assimilates resulting from augmented sink strength through endogenously produced plant growth regulators within the developing grain (Warner et al., 1987). In this finding, it is evident that the new plant types have better grain filling in the early stage.

Grain growth rate $(\mathbf{g} / \mathbf{g} / \mathbf{d a y})$ : The grain growth rate (GGR) of the seeds decreased continuously from 5-15 DAA to 35 DAA-harvest in all the genotypes (Table 1). It was further observed that the rate was more in the hexaploids at all the stages. At 5-15 DAA, the genotype DL- 1266-2 belonging to hexaploids recorded significantly higher GGR, but was at par with other hexaploids and also with PDW-233 of tetraploids. Darroch and Baker (1990) have reported about the significant genotypic differences in rate and duration of grain filling in spring wheat. The lower GGR was also recorded in HI-8498 of tetraploids. At 15-25 DAA, the genotype DL-1266-1 recorded higher GGR but was at par with genotypes in hexaploids and also with PDW-233 of tetraploids. Significantly lower GGR $(0.077 \mathrm{~g} / \mathrm{g} / \mathrm{day})$ was recorded in HI-8498 of tetraploids when compared to all other genotypes. Similarly, at 25-3 5 DAA also, DL-1266-1 of hexaploids recorded significantly higher GGR but was at par with other hexaploids. At 35 DAA-harvest, the genotypes did not show any significant differences. Interestingly, it was observed that GGR, was higher in hexaploids than tetraploids and growth rate was maximum immediately after anthesis till 25 DAA. The hexaploids showed greater growth rate in the first 15 days and slightly reduced in next 10 days as against uniform growth rate in tetraploids during this period. But in both the types, the GGR was almost negligible after 35 DAA. Sayed and Gadallah (1983) reported that grain yield in wheat was more ciosely related to the rate than the duration of grain filling, whereas Gebeyehou et al. (1982) found that both rate and duration of grain filling were positively associated with final grain weight. In the present investigation, it was found that the hexaploids (new plant types) possessed maximum grain growth rate at 5-15 DAA and DL- $1266-2$ recorded the highest growth rate $(0.093 \mathrm{~g} / \mathrm{g} / \mathrm{day})$. This initial growth rate might have contributed for better grain filling and grain weight of DL-1266-2 (61.25 mg/grain).

Hormonal regulation of seed development: Results showed that the endogenous hormonal contents in grains during grain development changed in sequence. At 5 DAA, $\mathrm{GA}_{3}$ content was maximum and at 15 DAA (rapid growth phase), IAA reached the maximum, while at 25 DAA (dough stage), the ABA was maximum. At 35 DAA, all the endogenous hormonal level decreased and ABA was highest followed by IAA and $\mathrm{GA}_{3}$. Among the genotypes, hexaploids recorded higher concentration of endogenous hormones compared to tetraploids 
(Fig. 1). Increase in $\mathrm{GA}_{3}$ content at early embryonic stage where a rapid enlargement of embryo (Qin and Tang, 1984) takes places implied hat $\mathrm{GA}_{3}$ had signaled the translocation of metabolites to the active sink, such as the developing grain (Monula et al., 1980). The characteristic decrease in $\mathrm{GA}_{3}$ content at 25 DAA can be explained by the hypothesis put forth by Krishnamoorty (1981) that at this stage, $\mathrm{GA}_{3}$ will exist in a storage form $\left(\mathrm{GA}_{3}\right.$ conjugate) and in matured grain, it will be used during germination. IAA content of the developing grains increased as the gains entered into the rapid grain growth phase (5-15 DAA). The increase in auxin concentration stimulates cell division, which in turn enhances the translocation of photosynthates towards developing sinks (Singh and Gerung, 1982). Abscisic acid content in the grain was found to be low at the early grain filling stage as also reported by Yang et al. (2001), but at 25 DAA (dough stage); it reached the highest level. Apart from synthesis of ABA by the inner layers of the pericarp containing chloroplasts (Radely, 1976), the hormone might have been translocated from other parts of the plant and resulted in higher concentration. The higher ABA concentration found in new plant types might have enhanced the import of assimilates and resulted in the higher grain filling and ultimately, higher grain weight and yield. There are also reports by earlier workers that the ABA is elevated in the grains during maturation for induction of dormancy. The higher levels of ABA (hard dough stage), minimal level of $\mathrm{GA}_{3}$ and intermediate levels of IAA at 35 DAA suggests that, at this stage, maintenance of embryo dormancy appears to be an active process involving ABA (Morris et al., 1991). The correlation between hormonal content at different days after anthesis and the grain growth rate (Table 2) among

Table 2. Coerrelation co-efficients between hormonal contents and grain growth rate among hexaploid and tertaploid wheat.

\begin{tabular}{l|llll}
\hline \multirow{2}{*}{$\begin{array}{c}\text { Hormones at different } \\
\text { days after anthesis }\end{array}$} & \multicolumn{4}{c}{ Grain growth rate at different days after anthesis } \\
\cline { 2 - 5 } IAA 5 DAA & \multicolumn{1}{|c}{5 -15 } & \multicolumn{1}{c}{$15-25$} & \multicolumn{1}{c}{$25-35$} & Harvest \\
\hline IAA 15 DAA & $0.971^{* *}$ & 0.651 & 0.060 & 0.607 \\
IAA 25 DAA & $0.881^{*}$ & 0.789 & 0.639 & 0.618 \\
IAA 35 DAA & $0.815^{*}$ & $0.829 *$ & $0.838^{*}$ & 0.841 \\
GA 5 DAA & $0.9694^{*}$ & 0.616 & 0.790 & $0.883^{*}$ \\
GA 15 DAA & $0.931^{*}$ & 40.575 & 0.570 & 0.605 \\
GA 25 DAA & $0.927^{* *}$ & 0.526 & 0.615 & 0.546 \\
GA 35 DAA & $0.849^{*}$ & 0.809 & 0.721 & 0.711 \\
ABA 5 DAA & $0.953^{* *}$ & 0.684 & 0.579 & $0.931^{* *}$ \\
ABA 15 DAA & $0.929^{* *}$ & 0.601 & 0.645 & 0.526 \\
ABA 25 DAA & $0.855^{*}$ & 0.440 & 0.313 & 0.546 \\
\hline ABA 35 DAA & $0.910^{*}$ & 0.459 & 0.614 & 0.387 \\
\hline
\end{tabular}

* Significant at $5 \%(\mathrm{r}=0.811)$; ** Significant at $1 \%(\mathrm{r}=0.917)$. 

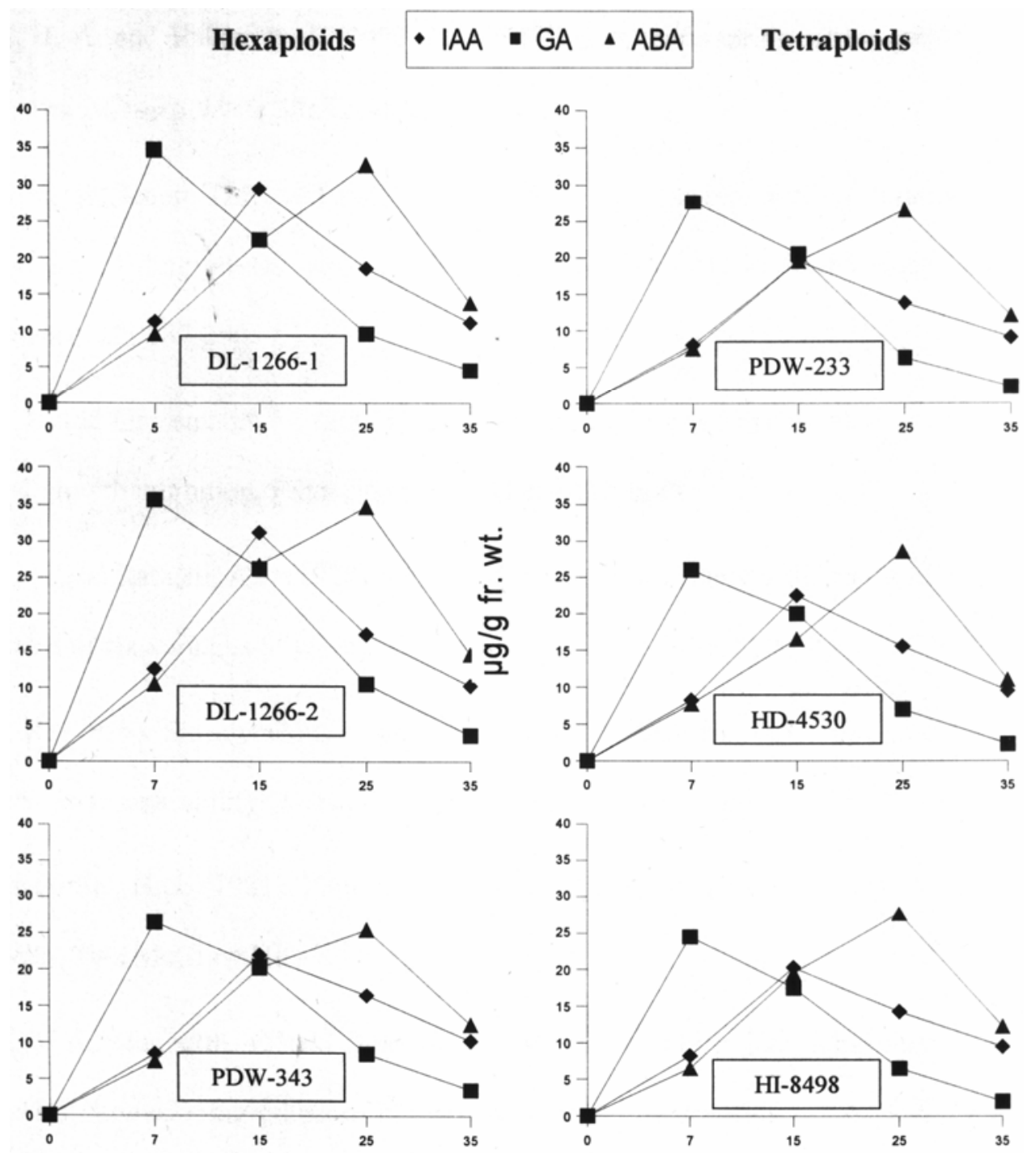

Days after anthesis

Fig. 1. Endogenous hormonal content in developing grains of hexaploid and teraploid wheat.

hexaploids and tetraploids of wheat indicated that highly significant correlation between the grain growth rate at 5-15 DAA and the endogenous hormonal content. This leads to the conclusions that the rapid grain growth phase (5-15 DAA) is crucial for any genotype and this phase has a significant correlation with the endogenous hormonal content in the developing grains. Haploids recorded higher concentration of endogenous hormones than tetraploids. The increase in 
$\mathrm{GA}_{3}$ content at the early embryonic stage, where a rapid enlargement of embryo takes place implies that $\mathrm{GA}_{3}$ had signaled the translocation of metabolites to the active sink, such as the developing grain. The increase in auxin concentration might have stimulated cell division and this could have created an attraction for the translocation of photosynthates. The higher ABA concentration in the hexaploids might have enhanced the import of assimilates and it resulted in the higher grain filling and ultimately, higher grain weight and yield.

\section{Acknowledgment}

The first author acknowledges Dr. S. S. Singh of Division of Genetics, IARI for proving planting material, Dr. (Ms.) Prem Dureja and Dr. Devkumar of Division of Agricultural Chemicals, IARI for HPLC analysis and Dr. M. B. Chetti, of Department of Crop Physiology, UAS, Dharwad for valuable comments and suggestions during the research and Dr. P. Manivel of NRCMAP, Anand for critically going through the manuscript.

\section{References}

Bhardwaj, S.N. and V. Verma. 1985. Hormonal regulation of assimilate translocation during grain growth in wheat. Indian Journal of Experimental Botany 23: 719-721.

Darroch, B. A. and Baker, R. J. 1990. Grain filling in three spring wheat genotypes: statistical analysis. Crop Science 30: 525-529.

Gebeyehou, G., D.R. Knott, and R.J. Baker. 1982. Relationships among durations of vegetative and grain filling phases, yield components, and grain yield in durum wheat cultivars. Crop Science 22: 287-290.

Hansen, H and K.Grossmann. 2000. Auxin-induced ethylene triggers abscisic acid biosynthesis and growth inhibition. Plant Physiology 124: 1437-1448.

Jenner C.F. and A.J. Rathjen. 1978. Physiological basis of genetic differences in the growth of the grains of six varieties of wheat. Australian Journal of Plant Physiology 5: 249-262.

Kojima, K. (1995). Simultaneous measurement of ABA, IAA and GA's in citrus- Role of BA in relation to sink ability. Journal of Agricultural Research Quarterly 29: 179-185.

Krishnamoorthy, H.N. 1981. Plant growth substances, including applications in agriculture, New Delhi, Tata McGraw Hill.

Monula, M.A., Bangerth, F. and Story, V. 1980. Gibberellins like substances and indole type auxins in developing grains of normal and high-lysine genotypes of barley. Plant Physiology 48: 568.

Morris, C.F., R.J. Anderberg, P.J. Goldmark, M.K. walker-Simons. 1991. Molecular cloning and expression of abscisic acid-responsive genes in embryos of dormant wheat seeds. Plant Physiology 95: 8 14-821. 
Panse, V. G. and P.V. Sukhatme. 1967. Statistical Methods for Agricultural Workers. ICAR, New Delhi.

Qin, Z. and Tang, X. 1984. Dynamics of some large biomolecules during the formation of rice endosperm. China Science 12: 1103-1110.

Radley, M. (1976). The development of wheat grain in relation to endogenous growth substances. Journal of Experimental Botany 27: 1009-102 1.

Sayed, H.I. and Gadallah, A.M. 1983. Variation in dry matter and grain filling characteristics in wheat cultivars. Field Crops Research 7: 61-71.

Singh, G. and Gerung; S.B. 1982. Hormonal role in the problem of sterility in Orizya Sativa. Plant Physiology Biochemistry 9: 22-23.

Sivakumar, T. Virendra Nath, G.C. Srivastava, 2001. Effects of benzyl adenine and abscisic acid on grain yield and yield components in triticale and wheat. Journal of Agromony and Crop Science 186: 43-46.

Sundberg, B. 1990. Influence of extraction solvent (buffer, methanol, acetone) and time on the quantification of indole-3-acetic acid in plants. Plant Physiology 78: 293-297.

Wardlaw, I.F and L. Moncur. 1976. Source, sink and hormonal control of translocation in wheat. Plan/a 128: 93-100.

Warner, A., S.N., Bhardwaj, P.C. Pande. 1987. Effect of BA on grain growth in aestivum wheat. Plant Cell Phsyiology. 28: 73 5-739.

Yang, J.C., S.B., Peng, Q.S. Zhu, and S.L. Gu. 2000. Grain filling pattern and cytokinin content in the grains and roots of rice plants. Plant Growth Regulation 30: 26 1-270.

Yang, J.C., J.H., Zhang, Z.Q., Wang, Q.S. Zhu, and L.J. Liu, 2001. Water deficit-induced senescence and its relationship to the remobilization of pre-stored carbon in wheat during grain filling. Agronomy Journal 93: 196-206.

Zhu, Q., Cao, X. and Y. Luo, 1988. Growth analysis on the process of grain filling in rice. Ac/a Agronomica Sinica 14: 182-193. 